\title{
PLANTAS DE CANA-DE-AÇÚCAR CULTIVADAS IN VITRO COM ANTIBIÓTICOS
}

\author{
Sugar cane plants cultivated in vitro with antibiotics
}

\author{
Virgínia Maria Tenório Sabino Donato ${ }^{1}$, Arnóbio Gonçalves de Andrade ${ }^{2}$, \\ Galba Maria de Campos Takaki ${ }^{3}$, Rosa de Lima Ramos Mariano ${ }^{4}$, Gabriel Alves Maciel ${ }^{5}$
}

\section{RESUMO}

A contaminação por microrganismos é conhecida como um dos mais sérios problemas da cultura de tecidos de plantas, especialmente, em espécies tropicais. Com o objetivo de eliminar bactérias endofíticas, propágulos das cultivares de cana-deaçúcar Co 997, SP 70-1143 e ápices caulinares isolados de plantas, provenientes de semente botânica biparental (RB 818004 x SP 71-6949), foram cultivados in vitro, em meios de cultivo com antibióticos. No primeiro experimento, propágulos das cultivares Co 997 e SP 70-1143 foram cultivados em meio de cultivo contendo 200 e $300 \mathrm{mg} . \mathrm{L}^{-1}$ de amoxicilina e cefatoxima sódica durante 30 dias. Num segundo experimento, utilizou-se apenas a amoxicilina em concentrações mais elevadas ( 300 , 600 e 1000 $\mathrm{mg} . \mathrm{L}^{-1}$ ), com as mesmas plantas utilizadas no primeiro experimento, permanecendo em cultivo por mais 30 dias. No terceiro experimento foram utilizados ápices caulinares isolados de plantas provenientes de semente botânica biparental (RB 818004 x SP 71-6949), cultivados em meio de cultivo contendo $1000 \mathrm{mg} . \mathrm{L}^{-1}$ de amoxicilina, por um período de 120 dias. Após estes períodos de cultivo, testes de infecção e observações histológicas revelaram que o isolamento do ápice caulinar associado ao uso de antibiótico no meio de cultivo não foi suficiente para eliminar as bactérias endofíticas.

Termos para indexação: Contaminação, bactérias, Acetobacter diazotrophicus, Saccharum sp.

\begin{abstract}
Contamination by microrganism is known as one of the most serious problems in plant tissue cultures, especially, of tropical species. Most of the time, this contamination is derived from endophytic bacteria. With the objective of eliminating the endophytic bacteria Acetobacter diazotrophicus and Herbaspirillum spp., propagules of the cultivars Co 997, SP 70-1143 and shoot tips of sugarcane plants, from botanical biparental seed (RB 818004 x SP 71-6949) were cultivated in vitro in culture media with antibiotic. In the first experiment, propagules of the cultivars Co 997 and SP 70-1143 were cultivated in culture media with 200 and 300 mg. $\mathrm{L}^{-1}$ of amoxicilin and sodic cephatoxin for 30 days. In the second experiment, plants from the first one were transferred to culture media containing amoxicilin in concentrations of 300, 600 and 1000 mg. $\mathrm{L}^{-1}$ for more 30 days. In the third experiment, shoot tips were cultivated in culture media with $1000 \mathrm{mg} . \mathrm{L}^{-1}$ of amoxicilin during 120 days. After these cultivation periods, infection tests and histological observations revealed that bacteria were not eliminated from sugarcane tissues.
\end{abstract}

Index terms: Contamination, bacteria, Saccharum sp.

( Recebido para publicação em 26 de novembro de 2003 e aprovado em 11 de janeiro de 2005)

\section{INTRODUÇÃO}

A propagação vegetativa in vitro, também denominada de micropropagação, é a aplicação mais prática e de maior impacto da cultura de tecidos, que tem como principal objetivo a limpeza clonal ou a aceleração dos métodos convencionais de propagação vegetativa (GRATTAPAGLIA e MACHADO, 1998).

Para a cana-de-açúcar, a propagação in vitro é bastante vantajosa, considerando que um dos maiores problemas enfrentados em programas de melhoramento genético convencional nessa cultura é a dificuldade de multiplicar o material selecionado com rapidez. Normalmente, antes da utilização da micropropagação, além dos 10 ou 15 anos de seleção, eram requeridos mais alguns anos para se estabelecer as novas cultivares em plantios comerciais.

A utilização do processo de limpeza clonal a partir da cultura de meristemas não garante totalmente a sanidade do material trabalhado (LIU, 1989; TORRES et al., 1998). A contaminação por microrganismos é conhecida como um dos mais sérios problemas da cultura de tecidos de plantas, especialmente, em espécies tropicais (KNEIFEL e LEONHARDT, 1992).

\footnotetext{
1. Bolsista FACEPE, Empresa Pernambucana de Pesquisa Agropecuária (IPA), R. João Ramos, 285/1801, Graças- 52011-080, Recife-PE. vmtsdonato@uol.com.br

2. Departamento de Química Vegetal/ UFRPE, R. D. Manoel de Medeiros s/n. Dois irmãos - 52171-900- Recife,PE.

3. Universidade Católica de Pernambuco (UNICAP), Rua do Príncipe, 526, Boa Vista - 50050-900, Recife,PE.

4. Departamento de Agronomia/ UFRPE.

5. Empresa Pernambucana de Pesquisa Agropecuária (IPA), Av. Gal. San Martin, 1371, Bongi, 50761-000, Recife,PE.
} 
Na maioria das vezes, essa contaminação é proveniente de bactérias endofíticas. No entanto, embora essas contaminações sejam indesejáveis, ocorrem casos onde o cultivo associado é uma opção, quando a bactéria é identificada como não patogênica (GRATTAPAGLIA e MACHADO, 1998).

Atualmente, sabe-se que a cana-de-açúcar está associada à bactérias fixadoras de nitrogênio. Entre essas bactérias, Acetobacter diazotrophicus (GILLIS et al., 1989) e Herbaspirillum spp. (BALDANI et al., 1996; GILLIS et al., 1991) têm sido consideradas as mais importantes pelo seu caráter endofítico obrigatório (BALDANI et al., 1997). A utilização da cultura de meristemas, para a produção de mudas de cana-de-açúcar, pode eliminar estas bactérias dos seus tecidos (REIS et al., 1999). Estudos recentes e mais detalhados revelam que tanto a A. diazotrophicus (JAMES et al., 1994), como Herbaspirillum spp. (OLIVARES et al., 1997) encontram-se internamente na planta colonizada, localizando-se nos tecidos vasculares e espaços intercelulares. A identificação destes diazotróficos endofíticos, como organismos responsáveis por grande contribuição à fixação biológica de nitrogênio em cana-de-açúcar, sugere a possibilidade de alcançar eficiência significante para outras gramíneas. Para avaliar o papel destas bactérias na fixação de $\mathrm{N}_{2}$, é desejável a obtenção de plantas isentas destes microrganismos para uso como testemunha.

A utilização de antibióticos para o controle e erradicação de microrganismos contaminantes é frequente, podendo os mesmos serem adicionados ao meio de cultura ou submetendo os explantes a banhos sob agitação, durante alguns dias (GRATTAPAGLIA e MACHADO, 1998). No entanto, o uso de antibióticos apresenta problemas, uma vez que eles podem apresentar níveis consideráveis de toxidez ao tecido vegetal (POLLOCK et al., 1983; SCORTICHINI e CHIARIOTTI, 1988). Além disto, antes da utilização de antibióticos, deve-se proceder a realização de uma prova de sensibilidade das bactérias contaminantes.

Desenvolveu-se este trabalho com o objetivo de eliminar bactérias endofíticas fixadoras de $\mathrm{N}_{2}$, presentes em plantas de cana-de-açúcar cultivadas in vitro, para obtenção de plantas totalmente limpas, a serem usadas como testemunhas na avaliação da real contribuição destes microrganismos para a cana-de-açúcar.

\section{MATERIAL E MÉTODOS}

O material vegetal utilizado para realização dos experimentos I e II foi fornecido pela Estação Experi- mental de Itapirema do IPA (Empresa Pernambucana de Pesquisa Agropecuária). Foram utilizados rebolos das cultivares SP 70-1143 e Co 997. Inicialmente, as gemas do rebolo foram individualizadas e tratadas com Kasugamicina $\left(3 \mathrm{~mL} \mathrm{~L}^{-1}\right)$, permanecendo submersas por 5 minutos, para diminuir a concentração de contaminantes, conseqüentemente, minimizando contaminações futuras, durante processo de cultivo in vitro. Outra parte das gemas foi submetida a um tratamento térmico de $52,5{ }^{\circ} \mathrm{C}$, durante 30 minutos. Subseqüentemente, as gemas foram plantadas em bandejas contendo substrato comercial (Plantmax ${ }^{\mathrm{R}}$ ) esterilizado, sendo mantidas em casa de vegetação. Após 20 dias do plantio, tanto as plantas originárias dos rebolos tratados com Kasugamicina $\left(3 \mathrm{~mL} \mathrm{~L}^{-1}\right)$, como aquelas submetidas ao tratamento térmico foram pulverizadas com a mesma solução de Kasugamicina (3mL L $\left.{ }^{-1}\right)$, com o objetivo de diminuir o índice de contaminação durante o processo de introdução do material vegetal no laboratório.

Uma semana após a pulverização com Kasugamicina e 21 dias após o tratamento térmico, os brotos foram seccionados e lavados em água corrente. Em seguida, foram eliminadas as folhas ficando apenas os mini-toletes, com aproximadamente $2,5 \mathrm{~cm}$ de comprimento, onde localiza-se o meristema apical. Posteriormente, os mini-toletes passaram por um processo de assepsia que consistiu na imersão em álcool a 70\% (v/v) por 1 minuto, em seguida em solução de hipoclorito de sódio a $2 \%(\mathrm{p} / \mathrm{v})$ durante 20 minutos e, finalmente, foram lavados 3 vezes em água destilada esterilizada. Os ápices caulinares foram isolados com o auxílio de lupa e, transferidos para tubos de ensaio contendo meio de cultura próprio para o cultivo de ápice caulinar de canade-açúcar, descrito por Liu (1980).

Após 60 dias de cultivo em sala de crescimento com temperatura de $24 \pm 1^{\circ} \mathrm{C}$ e fotoperíodo de 12 horas de luz, a planta matriz, quando totalmente diferenciada, proveniente do ápice caulinar isolado foi multiplicada sucessivamente a cada 15 dias até o quarto subcultivo. A presença das bactérias A. diazotrophicus e Herbaspirillum spp., nas plantas matrizes foi avaliada por teste de infecção. Para realização do teste de infecção, tomou-se uma porção de tecido das plantas estudadas, que foram submetidos a um processo de esterilização superficial constituído por álcool 70\% (13mim.), cloramina T 1\% (10 mim.) e finalmente água destilada estéril. Posteriormente, foram transferidos para frascos contendo meio de cultura próprio para cada bactéria, LGIP (A. diazotrophicus) e JNFB (Herbaspirillum spp.) (DÖBEREINER et al., 1995), e mantidos em estufa bacteriológica. 
As bactérias A. diazotrophicus e Herbaspirillum spp., isoladas das plantas micropropagadas, foram levadas ao Laboratório de Fitobacteriologia da Universidade Federal Rural de Pernambuco (UFRPE), onde realizou-se uma prova de sensibilidade (antibiograma) a dez antibióticos 1-(amoxicilina $(10 \mathrm{mcg}), 2$-carbenicilina $(100 \mathrm{mcg})$, 3-eritromicina (15 mcg), 4-estreptomicina $(10 \mathrm{mcg})$, 5-gentamicina (10 mcg), 6-neomicina (30 mcg), 7-norfloxacin (10 mcg), 8-polimixina b (300 mcg), 9-rifampicina (5 mcg) e 10-tetraciclina (30 mcg).

Para a realização do antibiograma, as bactérias foram cultivadas por 24-48 horas em meio NYDANutrient Yest Dextrose Agar (MARIANO et al., 2000). Posteriormente, com o auxílio de alça de platina, o crescimento bacteriano foi transferido para tubos de ensaio contendo aproximadamente $1 \mathrm{ml}$ de água destilada esterilizada, preparando-se as suspensões. Cada suspensão bacteriana foi adicionada a $200 \mathrm{~mL}$ do meio de cultura NYDA, que em seguida foi vertido em placas. Logo após solidificação do meio, para cada bactéria, foram plaqueados quatro discos de cada antibiótico por placa, com 4 repetições. A avaliação foi realizada medindo-se o halo de inibição do crescimento, em mm, após um período de 48 horas de incubação em estufa bacteriológica a $30^{\circ} \mathrm{C}$.

Conhecido o resultado do teste de sensibilidade, foram elaborados experimentos, cultivando as cultivares descritas acima em meio de cultura constituído apenas dos sais do MS (MURASHIGE e SKOOG, 1962) acrescido de dois antibióticos, a amoxicilina selecionada pelo antibiograma e a cefatoxima sódica incluida com base na literatura (DUHEM et al., 1988). No experimento I, foram utilizadas separadamente duas concentrações, 200 e $300 \mathrm{mg} \mathrm{L}^{-1}$, para os dois antibióticos. O experimento I teve delineamento inteiramente casualizado, com arranjo fatorial 2x2x2 (2 cultivares (Co 997 e SP 70-1143) x 2 antibióticos (amoxicilima e cefatoxima sódica) x 2 concentrações (200 e $300 \mathrm{mg} . \mathrm{L}^{-1}$ ), totalizando 8 tratamentos com 10 repetições.

No experimento II, utilizou-se apenas a amoxicilina em concentrações mais elevadas (300, 600 e 1000 mg. $\mathrm{L}^{-1}$ ), com as mesmas cultivares cultivadas no experimento I. O experimento II teve delineamento inteiramente casualizado, com arranjo fatorial 2x3 (2 cultivares (Co 997 e SP 70-1143) x 3 concentrações (300, 600 e $1000 \mathrm{mg} . \mathrm{L}^{-1}$ ), totalizando 6 tratamentos com 10 repetições. Os antibióticos esterilizados por filtração (filtro Millipore), foram adicionados ao meio MS, em câmara asséptica de fluxo laminar após a autoclavagem, quando a temperatura do meio de cultura baixou para $40^{\circ} \mathrm{C}$.
Em seguida, o meio foi distribuído em potes de vidro sob condições assépticas. Após 30 dias de cultivo, foram selecionadas, ao acaso, 4 das 10 repetições para realização do teste de infecção segundo Döbereiner et al. (1995), com a finalidade de verificar a presença ou ausência de A. diazotrophicus e Herbaspirillum spp.

No terceiro experimento, utilizaram-se ápices caulinares isolados de plantas provenientes de semente botânica biparental (RB 818004 x SP 71-6949), oriundos da Estação Experimental de Carpina - PE. Os ápices caulinares de 30 indivíduos, subsequentemente, foram cultivados em meio MS com $1000 \mathrm{mg} . \mathrm{L}^{-1}$ de amoxicilina por 120 dias. Após este período, os ápices caulinares diferenciados foram subcultivados por mais 30, 60, 90 e 120 dias com a mesma concentração de amoxicilina, quando os testes de infecção foram realizados, transferindo-se segmentos foliares dos indivíduos estudados em frascos, contendo $5 \mathrm{~mL}$ do meio de cultura Müller Hinton (BARRY, 1986), específico para o crescimento de bactérias, sendo incubados a $35^{\circ} \mathrm{C}$. Foram utilizados como tratamentos a planta diferenciada e mantida com antibiótico por 120 dias, plantas retiradas do antibiótico por $24,48,72,120$ e 240 horas e uma planta testemunha proveniente do cultivo in vitro sem antibiótico. Estudos histológicos foram realizados utilizando o método descrito por Patriquin e Döbereiner (1978).

\section{RESULTADOS E DISCUSSÃO}

O uso do Kasumin (Kasugamicina) associado ao tratamento termoterápico ou apenas o tratamento termoterápico, foram realizados com o objetivo de eliminar ou pelo menos diminuir a concentração de contaminantes nos tecidos da planta, para que fosse possível isolar o ápice caulinar com o mínimo de contaminação. Normalmente, o tratamento térmico é utilizado pelas industrias sucroalcooleiras para controlar o raquitismo da soqueira, causado pela bactéria Leifsonia xyli subsp. xyli. No entanto, este processo não foi eficiente para eliminar A. diazotrophicus e Herbaspirillum spp., uma vez que, após a diferenciação dos ápices caulinares, os testes de infecção revelaram a presença das bactérias nos tecidos das plantas estudadas.

Para verificar a sensibilidade das bactérias acima referidas, realizou-se um antibiograma que revelou que entre os antimicrobianos estudados, as bactérias apresentaram maior sensibilidade a amoxicilina. Então, este antibiótico foi adicionado ao meio de cultivo utilizado para multiplicar in vitro plantas de cana-de-açúcar, cultivares Co 997 e SP 70-1143, durante 30 dias. 
Um outro antimicrobiano, a cefatoxima sódica, apesar de não ter sido utilizado no antibiograma foi também adicionado ao meio de cultivo, devido a sua ampla utilização no controle de contaminantes durante o cultivo in vitro de outras culturas como o café e o cacau. Nesses trabalhos (DUHEM et al., 1988) observaram que a presença da cefatoxima sódica no meio de cultivo, promovia o controle da contaminação, além de não causar efeito tóxico para às plantas. Então, a cefatoxima sódica foi selecionada para compor o meio de cultivo para multiplicação in vitro da cana-de-açúcar, juntamente com a amoxicilina.

Os testes de infecção realizados por inoculação de fragmentos do tecido vegetal em meio específico para cada bactéria (JNFB para Herbaspirillum e LGIP para A. diazotrophicus (DÖBEREINER et al., 1995), revelaram após 34 dias o crescimento de película característica da bactéria
Herbaspirillum spp. no meio JNFB. No entanto, o crescimento de A. diazotrophicus não foiobservado no meio LGIP (DÖBEREINER et al., 1995) (Tabela 1).

Diante dos resultados observados, aquelas plantas cultivadas anteriormente em 200 e $300 \mathrm{mg} \mathrm{L}^{-1}$ dos antibióticos amoxicilina e a cefatoxima sódica, foram subcultivadas, por mais 30 dias, em novo experimento com concentrações de 300, 600 e $1000 \mathrm{mg} \mathrm{L}^{-1}$ utilizandose desta vez, apenas a amoxicilina. O novo teste de infecção mostrou que houve crescimento apenas no meio de cultura LGIP, próprio para a A. diazotrophicus (Tabela 2), embora as características do crescimento não fossem próprias desta bactéria, conforme Döbereiner et al. (1995), pois a película crescida no meio LGIP era branca e a coloração do meio de cultura passou de amarelo alaranjado para verde escuro.

TABELA1 - Teste de infecção para Acetobacter diazotrophicus e Herbaspirillum spp., em cultivares de cana-de-açúcar cultivadas in vitro em meio de cultura com antibióticos por 30 dias.

\begin{tabular}{|c|c|c|c|c|}
\hline \multirow{3}{*}{ Antibióticos (mg.L $\left.{ }^{-1}\right)$} & \multicolumn{4}{|c|}{ Cultivares/Meios de Cultura } \\
\hline & \multicolumn{2}{|c|}{ CO 997} & \multicolumn{2}{|c|}{ SP 70-1143 } \\
\hline & LGIP $^{1}$ & $\mathrm{JNFB}^{2}$ & LGIP & JNFB \\
\hline Amoxicilina 200 & - & + & - & + \\
\hline Amoxicilina 300 & - & + & - & + \\
\hline Cefatoxima Sódica 200 & - & + & - & + \\
\hline Cefatoxima Sódica 300 & - & + & - & + \\
\hline
\end{tabular}

${ }^{1}$ LGIP (Meio de cultura específico para $A$. diazotrophicus); ${ }^{2}$ JNFB (Meio de cultura específico para Herbaspirillum spp.). (+) crescimento positivo, (-) crescimento negativo. Foram utilizadas 10 repetições para cada tratamento (concentração/cultivar/JNFB ou LGIP).

TABELA 2 - Teste de infecção para Acetobacter diazotrophicus e Herbaspirillum spp., em cultivares de cana-de-açúcar cultivadas in vitro, por 30 dias, em meio de cultura com diferentes doses de amoxicilina.

\begin{tabular}{|c|c|c|c|c|}
\hline \multirow{3}{*}{ Amoxicilina (mg. $\left.\mathrm{L}^{-1}\right)$} & \multicolumn{4}{|c|}{ Cultivares/Meios de Cultura } \\
\hline & \multicolumn{2}{|c|}{ CO 997} & \multicolumn{2}{|c|}{ SP 70-1143 } \\
\hline & LGIP $^{1}$ & $\mathrm{JNFB}^{2}$ & LGIP & JNFB \\
\hline 300 & + & - & + & - \\
\hline 600 & + & - & + & - \\
\hline 1000 & + & - & + & - \\
\hline
\end{tabular}

${ }^{1}$ LGIP (Meio de cultura específico para A. diazotrophicus); ${ }^{2}$ JNFB (Meio de cultura específico para Herbaspirillum sp). (+) crescimento positivo, (-) crescimento negativo. Foram utilizadas 10 repetições para cada tratamento (concentração/cultivar/JNFB ou LGIP). 
O crescimento bacteriano observado nos frascos contendo meio LGIP foi transferido para placas com os meios LGIP e JNFB, seletivos para cada bactéria, com a finalidade de observar as características de crescimento das colônias. Nas placas com o meio LGIP não foi observado crescimento. Entretanto, naquelas com JNFB observou-se o crescimento de colônias características da bactéria Herbaspirillum spp. (DÖBEREINER et al., 1995). Além disso, lâminas foram preparadas e com o auxílio de um microscópio óptico, observou-se células em forma de bastão apresentando movimento espiralóide, quando próximas a bolhas de ar. Desta forma, verificou-se que as concentrações dos antibióticos não foram eficientes para eliminar Herbaspirillum spp. Entretanto, aparentemente, A. diazotrophicus apresentou maior sensibilidade aos antibióticos utilizados, pois não foi mais observado crescimento desta bactéria após diversos testes de infecção.

Acredita-se que como as plantas das quais foram retirados os tecidos para realizar os testes de infecção, estavam submetidas a elevada concentração de antibiótico desde do início da sua introdução in vitro, cerca de 120 dias, o tecido utilizado nos testes apresentavam elevada concentração de antibiótico, impedindo o crescimento da bactéria. Aquele crescimento observado no meio LGIP, possivelmente foi proveniente de indivíduos que tenham adquirido resistência ao antibiótico acima referido. Outra possibilidade é a pequena presença das bactérias na planta devido ao cultivo continuado com antibiótico, sendo que aquele tecido que foi utilizado para o teste de infecção no meio LGIP continha algum indivíduo que por sobrevivência conseguiu adaptar-se e crescer no meio LGIP mesmo não sendo o mais adequado.

A utilização de antibióticos no cultivo in vitro, é interessante para o controle de contaminações bacterianas endógenas que freqüentemente representam sérios problemas no estabelecimento in vitro das culturas (GRATTAPAGLIA e MACHADO, 1998). No entanto, é consenso que mesmo assim, dificilmente se consegue eliminar completamente as bactérias, pois os antibióticos normalmente utilizados em cultura de tecidos vegetais possuem ação bacteriostática e não bactericida. Isto explica porque neste trabalho, o uso de antibióticos em plantas de cana-de-açúcar cultivadas in vitro para eliminar as bactérias endofíticas não foi eficiente. Aparentemente, houve ação bacteriostática, paralisando, mas não eliminando o crescimento bacteriano nos tecidos da planta. Duhem et al. (1988), também observaram que em café e cacau, o uso de antibióticos no meio de cultu- ra, além de aumentar a oxidação dos explantes, apenas paralisou o crescimento das bactérias, mas não as eliminou.

O uso de antibióticos não foi efetivo para a eliminação de Herbaspirillum spp quando utilizados propágulos como explantes. Então, foram cultivados ápices caulinares isolados direto em meio de cultivo contendo alta concentração de amoxicilina (1000 $\left.\mathrm{mg} \mathrm{L}^{-1}\right)$. Os ápices caulinares utilizados nesta etapa foram provenientes de plantas diferenciadas de semente botânica biparental (RB 818004 x SP- 716949). Foram isolados 30 ápices caulinares e cultivados em meio de cultivo com amoxicilina. Destes, apenas $6 \%$ regeneraram planta, provavelmente pela sua toxidez. As plantas regeneradas foram cultivadas na presença da mesma concentração de amoxicilina por mais 30, 60 e 120 dias. Após este período de cultivo associado com antibiótico, realizaram-se testes de infecção.

Sete dias após a inoculação, observou-se que não houve crescimento de bactérias nos tecidos da planta cultivada com amoxicilina nem naqueles retirados do antibiótico por 24, 48, 72, 120 e 240 horas, enquanto nos tecidos da planta testemunha, diferenciada e cultivada sem antibiótico, houve crescimento bacteriano após 24 h da inoculação. Acredita-se que o uso prolongado de antibiótico no meio de cultura, tenha diminuído a concentração e inibido o crescimento da bactéria. Além disso, possivelmente a presença de resíduos do antibiótico nos tecidos tenha impedido o crescimento bacteriano, durante o período de avaliação.

Cortes longitudinais e transversais de tecido fresco de cana-de-açúcar, cultivada com e sem antibiótico, foram incubados em solução de tetrazólio, para verificar a presença de bactérias (PATRIQUIN e DÖBEREINER, 1978). As áreas de cor vermelhointenso ou púrpuro indicam a presença de bactérias, até mesmo naquelas plantas cultivadas com antibiótico, embora, com menor reação que na planta testemunha (Figura 1A). A redução pelo tetrazólio pode ocorrer em bactérias fixadoras de $\mathrm{N}_{2}$ ou não (DÖBEREINER e DAY, 1976; PATRIQUIN e DÖBEREINER, 1978). No entanto, verificou-se pelos exames microscópicos dos tecidos estudados, que as bactérias presentes apresentavam movimentos espiralados quando próximos à bolhas de ar, característicos da Herbaspirillum spp., segundo a descrição de Döbereiner et al. (1995).

No presente trabalho, bactérias foram comumente observadas nas plantas testemunhas, nas plantas retiradas do antibiótico (Figura 1B) e nas plantas cultivadas com antibiótico (1000 mg L $\mathrm{m}^{-1}$ de amoxicilina) (Figura 1C). 
Esta técnica foi utilizada anteriormente por Patriquin et al. (1980), para localizar bactérias fixadoras de $\mathrm{N}_{2}$ em plantas de cana-de-açúcar. Portanto, constatou-se que a prática do cultivo de ápices caulinares desta cultura na presença de $1000 \mathrm{mg} \mathrm{L}^{-1}$ de amoxicilina, por vários subcultivos, não eliminou as bactérias presentes nos tecidos, funcionando apenas como bacteriostático. Estes resultados contrariam a afirmativa de que a utilização da cultura de ápices caulinares, para a produção de mudas de cana-de-açúcar, pode eliminar as bactérias fixadoras de $\mathrm{N}_{2}$ dos seus tecidos, relatado por Reis et al. (1999). Por outro lado, concordam com Liu (1989) e Torres et al. (1998), quando afirmam que a utilização do processo de limpeza clonal, a partir da cultura de meristemas ou ápices caulinares, não garante totalmente a sanidade do material trabalhado.

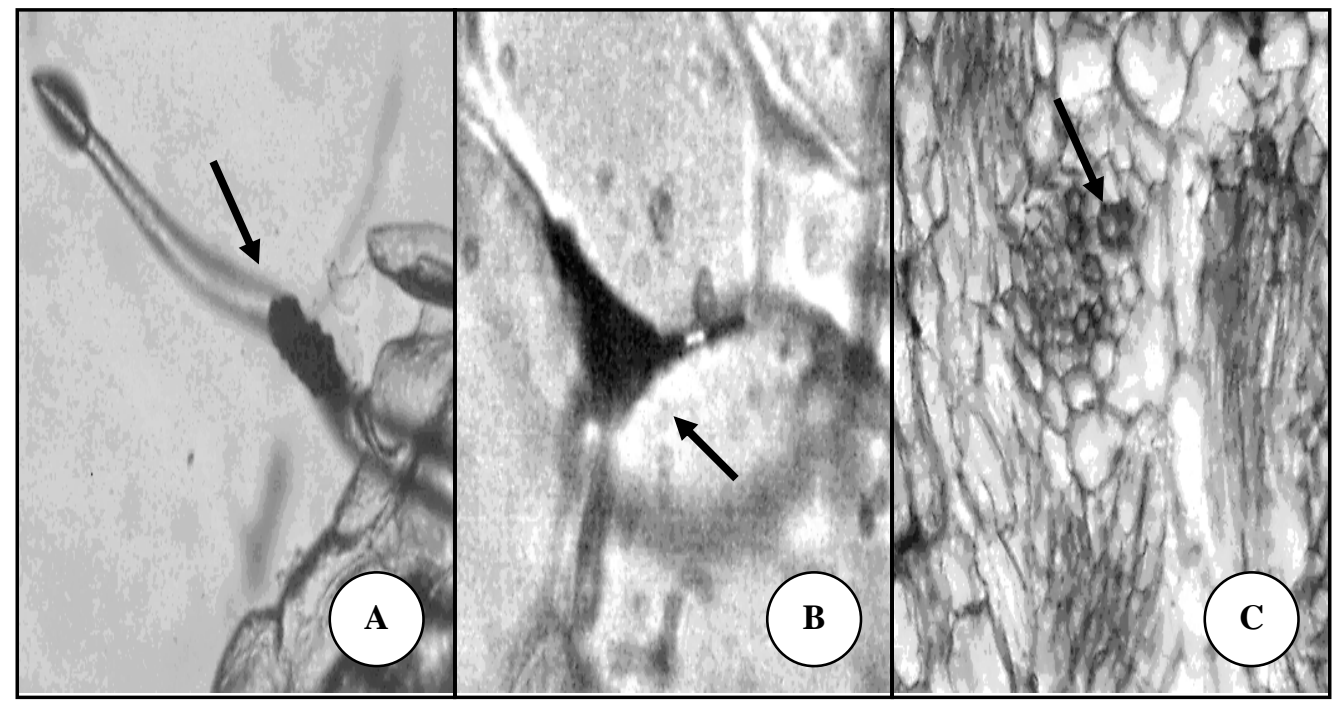

FIGURA 2 - Estudo histológico em tecido fresco de planta de cana-de-açúcar cultivada in vitro : (A)Secção longitudinal de plantas cultivada e diferenciada sem antibiótico (testemunha); (B) Secção transversal de plantas retirada do antibiótico por 24h; (C) Secção transversal de plantas cultivada com $1 \mathrm{~g} \mathrm{~L}^{-1}$ de amoxicilina (400x).

\section{CONCLUSÕES}

a) O cultivo de ápices caulinares de cana-deaçúcar não eliminou as bactérias fixadoras de $\mathrm{N}_{2}$ dos seus tecidos.

b) A amoxicilina foi o antibiótico mais eficiente na inibição do crescimento das bactérias Acetobacter diazotrophicus e Herbaspirillum spp.

c) O uso dos antibióticos amoxicilina e cefatoxima sódica, no meio de cultura nas concentrações empregadas foi eficiente para eliminar a bactéria endofítica Acetobacter diazotrophicus, em plantas de cana-deaçúcar.

d) O uso dos antibióticos amoxicilina e cefatoxima sódica, no meio de cultura nas concentrações empregadas não foi eficiente para eliminar a bactéria endofítica Herbaspirillum spp., em plantas de canade-açúcar quando se utilizou tanto propágulos quanto ápices caulinares como fonte de explantes.

\section{AGRADECIMENTOS}

À Carmelita Cavalcante e ao prof. José Figueredo (LIKA - UFPE), pela disponibilidade durante a realização dos cortes histológicos.

\section{REFERÊNCIAS BIBLIOGRÁFICAS}

BALDANI, J. I. et al. Recent advances in BNF with non-legume plants. Soil Biology and Biochemistry, Elmsford, v. 29, p. 911-922, 1997.

BALDANI, J. I. et al. Emended description of Herbaspirillum; inclusion of (Pseudomonas) rubrisubalbicans, a mild plant pathogen, as Herbaspirillum rubrissubalbicans comb.nov.; and classification of a group of clinical isolates (EF group 1) as Herbaspirillum species 3. Internacional Journal of Systematic Bacteriology, [S.l.], v. 14, p. 263-279, 1996. 
BARRY, A. L. Procedure for testing antimicrobial agents in agar media: theoretical considerations. In: LORIAN, V. Antibiotics in laboratory medicine. Baltmore: Williams \& Wilkins, 1986. p. 1-26.

DÖBEREINER, J.; BALDANI, V. L. D.; BALDANI, J. I. Como isolar e identificar bactérias diazotróficas de plantas não-leguminosas. Brasília: EMBRAPACNPAB, 1995. 60 p.

DÖBEREINER, J.; DAY, J. M. Associative symbiosis in tropical grass: characterization of microorganisms and dinitrogen-fixing sites. In: INTERNATIONAL SYMPOSIUM ON N 2 FIXATION, 1., 1976, Washington. Proceeding... Pullman: Washington State University, 1976. p. 518-537.

DUHEM, F.; MERCIER, N.; BOXUS, P. Difficulties in the establishment of axenic in vitro cultures of field collected coffee and cacao germplasm. Acta Horticulturae, The Hague, v. 225, p. 67-75, 1988.

GILLIS, M. et al. Taxonomy relationship between Pseudomonas rubrisubalbicans, some clinical isolates (EF group I), Herbaspirillum seropedicae and Aquaspirillum autotrophicum. In: POLSINELLI, M.; MATERASSI, R.; VICENZINI, M. (Eds.). Nitrogen fixation. Dordrecht: Kluwer Academic, 1991. p. 292294.

GILLIS, M. et al. Acetobacter diazotrophicus sp. nov., a nitrogen-fixing acetic acid bacterium associated with sugarcane. International Journal of Systematic Bacteriology, [S.1.], v. 7, p. 361364, 1989.

GRATTAPAGLIA, D.; MACHADO, M. A. Micropropagação. In: TORRES, A. C.; CALDAS, L. S.; BUSO, A. J. (Eds.). Cultura de tecidos e transformação de plantas. Brasília: EMBRAPA-SPI/CNPH, 1998. v. 1 , p. $183-260$.

JAMES, E. K. et al. Infection of sugar cane by the nitrogen-fixing bacterium Acetobacter diazotrophicus. Jornal of Experimental Botany, Oxford, v. 45, p. 757766, 1994.

KNEIFEL, W.; LEONHARDT, W. Testing of different antibiotics against Gram-positive and Gram-negative bacteria isolated from plant tissue culture. Plant Cell,
Tissue and Organ Culture, Dordrecht, v. 29, p. 139$144,1992$.

LIU, L. J. Biotechnology: its potential importance for controling sugar cane diseases in Latin America and the Caribbean. In: INTER-AMERICA SUGAR CANE SEMINAR, 1989. Proceedings... [S.l.: s.n.], 1989. p. 332-335.

LIU, M. C. In vitro methods applied to sugarcane improvement. In: THORPE, T. A. (Ed.). Plant tissue culture. New York: Academic, 1980. p. 99-323.

MARIANO, R. L. R.; SILVEIRA, E. B.; ASSIS, S. M. P. Identificação de bactérias fitopatogênicas. In: MARIANO, R. L. R. (Coord.). Manual de práticas em fitobacteriologia. Recife: Universitária, 2000. p. 67-108.

MURASHIGE, T.; SKOOG, F. A. Revised medium for rapid growth and bioassays with tobacco tissue cultures. Physiologia Plantarum, Copenhagen, v. 15, p. 473497, 1962.

OLIVARES, F. L. et al. Infection of mottled stripe disease-susceptible and resistant sugar cane varieties by the endophytic diazotroph Herbaspirillum. New Phytopatologist, Saint Paul, v. 135, p. 723-737, 1997.

PATRIQUIN, D. G.; DÖBEREINER, J. Light microscopy observations of tetrazolium-reducing bacteria in the endorhizosphere of maize and other tropical grasses in Brazil. Canadian Journal of Microbiology, Ottawa, v. 24, p. 734-742, 1978.

PATRIQUIN, D. G.; GRACIOLI, L. A.; RUSCHEL, A. P. Nitrogenase activity of sugar cane propagated from stem cuttings in sterile vermiculite. Soil Biology and Biochemistry, Elmsford, v. 12, p. 413-417, 1980.

POLLOCK, K.; BARFIELD, D. G.; SHIELDS, R. The toxicity of antibiotics to plant cell cultures. Plant Cell Report, [S.1.], v. 2, p. 36-39, 1983.

REIS, V. M. et al. Technical approaches to inoculate micropropagated sugar cane plants were Acetobacter diazotrophicus. Plant and Soil, The Hague, v. 206, p. 205-211, 1999. 
SCORTICHINI, M.; CHIARIOTTI, A. In vitro culture of Prunus persica var. laevis gray (Nectarine): detection of bacterial contaminants and possibility of decontamination by means of antibiotics. Acta Horticulturae, The Hague, v. 225, p. 109-118, 1988.
TORRES, A. C.; TEIXEIRA, S. L.; POZZEWR, L. Cultura de ápices caulinares e recuperação de plantas livres de vírus. In: TORRES, A. C.; CALDAS, L. S.; BUSO, A. J. (Eds.). Cultura de tecidos e transformação de plantas. Brasília: EMBRAPA-SPI/CNPH, 1998. v. 1, p. 183-260. 